\title{
Physical and Organic Chemistry of Amine Scrubbing
}

\section{Valentin Talsi*}

Institute of Hydrocarbon Processing Problems, Siberian Branch, Russian Academy of Sciences, Russia

\begin{abstract}
The results of a multi-year NMR research in the field of physical and organic chemistry related to the problems of amine scrubbing are compiled. The revisited analysis of 2-aminoethanol degradation products has finally led to an adequate NMR signal assignment. This made it possible to suggest refined mechanisms of degradation reactions that lead to formation of compounds which are in particular responsible for corrosion of equipment and absorbent foaming.

Amine scrubbing has been an established technology over the past several decades for removal of acid gases $\left(\mathrm{H}_{2} \mathrm{~S}, \mathrm{CO}_{2}, \mathrm{SO}_{2}, \mathrm{COS}, \mathrm{CS}_{2}, \mathrm{NO}_{x}\right)$ from gaseous streams in the chemical and oil industries In recent time, the importance of studies in this field is justified by the global greenhouse gases reduction issue and potential use of 2-aminoethanol for binding $\mathrm{CO}_{2}$ here are two sets of problems relating to physical and organic chemistry of amine scrubbing. One of them concerns structural analysis of the salts formed by reaction of heterocumulenes $\mathrm{CO}_{2}, \mathrm{COS} \mathrm{CS}_{2}$ with amines. Another one is identification of degradation products of 2-aminoethanol, which is the most popular reagent for amine scrubbing. Carbamate and thiocarbamate salts obtained by the reaction of $\mathrm{CO}_{2}, \mathrm{COS}_{2} \mathrm{CS}_{2}$ with amines are used in important technologies of production of fertilizers, pesticides and regulators for tire industry.
\end{abstract}

Keywords: Amine scrubbing; Carbamate; Greenhouse gases; NMR; Thiocarbamate salts

\section{Introduction}

In earlier research, formation and acid catalyzed decomposition of the salts formed as the result of reaction of $\mathrm{CO}_{2}, \mathrm{COS}, \mathrm{CS}_{2}, \mathrm{CSe}_{2}$ with amines was studied by kinetic methods [1-5]. Zwitter ionic structure of dithio carbamic acids was first suggested by Ref. [6-11]. Chakravarty [12] modified the suggested structure in the following way. It was shown that stability of the salts obtained in the reaction of heterocumulenes with amines increased in the raw $\mathrm{CO}_{2}, \mathrm{COS}, \mathrm{CS}_{2}$, $\mathrm{CSe}_{2}$. The fact was explained by a rise of the bond polarizability in the sequence $\mathrm{C}-\mathrm{O}, \mathrm{C}-\mathrm{S}, \mathrm{C}-\mathrm{Se}$ and as a result by the increase of urethane bond energy because of more effective charge delocalization Schemes 1-3 which is a kind of well-known amide conjugation. The conjugation is the cause of a hindered rotation around amide and urethane bonds. Determination of the value of the hindered rotation barrier (mainly kinetic parameter $\Delta \mathrm{G}^{\neq}$in Eiring-Polanyi equation) is a classic example of dynamic NMR application. The following mechanism (Scheme 4) of acid catalyzed decomposition of carbamate and thiocarbamate salts

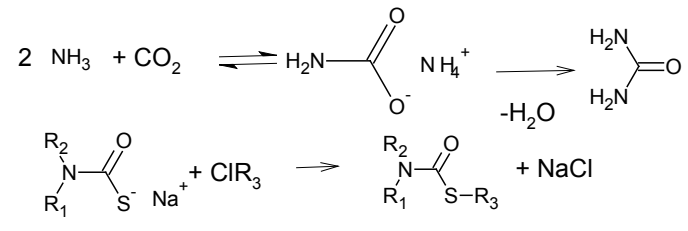

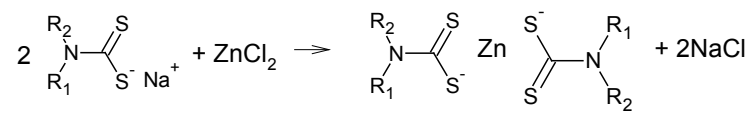

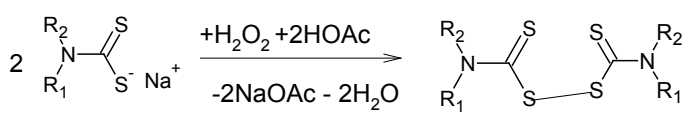

Scheme 1: Industrial reactions carbamate and thio carbamate salts.<smiles>[R2][N+]([R2])([R2])C(=S)S</smiles>

Scheme 2: Modified Zwitter ionic structure of dithiocarbamic acid was published in 1980 as follows [13]. As a rule, specific acid catalysis is observed for the most of salts. It means that the limiting stage of the reaction is formation and decay of dipolar intermediate. Only in case of carbamates of low basic amines such as 2 -aminoethanol a general acid catalysis takes place. The fact agrees with the observed loss of absorption capacity as the result of 2-aminoethanol oxidative degradation to carboxylic acids during the scrubbing, $\mathrm{pH}$ of absorbent being not substantially reduced. Solutions (in $\mathrm{CHCl}_{3}$ ) of the solid salts obtained by reactions of $\mathrm{CO}_{2}, \mathrm{COS}, \mathrm{CS}_{2}$ with secondary amines in petroleum ether were investigated with ${ }^{1} \mathrm{H},{ }^{13} \mathrm{C}$ NMR [14]. It was shown that equilibrium pictured on Scheme 4 for carbamates is strongly displaced to the left in organic solvents. Separate signals of<smiles>[Y]C([O-])=[N+]([R2])[R2]</smiles>

$\mathrm{X}=\mathrm{O}, \mathrm{S}, \mathrm{Se}$

Scheme 3: Amide conjugation in urethanes.

$$
\text { (1) }
$$

Scheme 4: Mechanism of hetero cumulenes with amines through unstable dipolar intermediate.

${ }^{*}$ Corresponding author: Talsi V, Institute of Hydrocarbon Processing Problems, Siberian Branch, Russian Academy of Sciences, Russia, Tel: +79659740961 . E-mail: vtalsi@ihcp.ru

Received November 18, 2016; Accepted December 28, 2016; Published January 04, 2017

Citation: Talsi V (2017) Physical and Organic Chemistry of Amine Scrubbing. Mod Chem Appl 5: 209. doi: 10.4172/2329-6798.1000209

Copyright: ( 2017 Talsi V. This is an open-access article distributed under the terms of the Creative Commons Attribution License, which permits unrestricted use, distribution, and reproduction in any medium, provided the original author and source are credited. 
cations and anions of carbamates in ${ }^{1} \mathrm{H},{ }^{13} \mathrm{C}$ NMR spectra can only be detected under cooling which enables estimation of kinetic parameter Gibbs energy of activation $\left(\Delta \mathrm{G}^{*}\right)$ for reversible reaction $\left[\mathrm{R}^{1} \mathrm{R}^{2} \mathrm{NCOO}^{-}\right]$ $\left[\mathrm{H}_{2} \mathrm{NR}^{1} \mathrm{R}^{2}\right]=\mathrm{CO}_{2}+2 \mathrm{HNR}^{1} \mathrm{R}^{2}$ (Table 1 ). In water solutions separate NMR signals of cations and anions of carbamates were detected at room temperature. The reality was used for a study of thiocarbamate hydrolysis with NMR [15]. Glazirin [15] suggested a rather complex mechanism and made subsequent detail kinetic study [16] the main result (Scheme 5) of the hydrolysis had been known, though. At the temperature increase the displacement of equilibrium at the Scheme 4 is reflected in a shift of NMR signals of alkyl ammonium cations to the frequencies which are characteristic of free amines. As the result, thermodynamic parameter enthalpy $(\mathrm{H})$ of the following decomposition of thiocarbamates was measured $\left[\mathrm{R}^{1} \mathrm{R}^{2} \mathrm{NCOS}-\right]$ $\left[\mathrm{H}_{2} \mathrm{~N}^{+} \mathrm{R}^{1} \mathrm{R}^{2}\right]=\mathrm{COS}+2 \mathrm{HNR}^{1} \mathrm{R}^{2}$ (Table 2). With the help of the method of dynamic NMR it also became possible to measure the value of the hindered rotation barrier $\left(\Delta \mathrm{G}^{\neq}\right)$in asymmetric thiocarbamate anions (Table 3). The authors of the paper considered possible to interpret the difference of values $\Delta \mathrm{G}^{\neq}, \Delta \mathrm{H}$ in Tables 1-3 in terms of subtle electronic (hyper conjugation) and steric effects of $\mathrm{N}$-alkyl substitutes. Recently $[17,18]$ it has been shown that carbamate and thiocarbamate anions formed as the result of reaction of $\mathrm{CO}_{2}$ and $\mathrm{COS}$ with 2-aminoethanol in water solutions have a specific cyclic structure (Scheme 6). The obtained high value of the hindered nitrogen pyramidal inversion barrier $\left(\Delta G^{\neq}\right)$is consistent with suggested three center two electron character of the hydrogen bond.

$\left[\mathrm{H}_{2} \mathrm{~N}^{+} \mathrm{R}^{1} \mathrm{R}^{2}\right]=\mathrm{CO}_{2}+2 \mathrm{HNR}^{1} \mathrm{R}^{2}$

\begin{tabular}{|c|c|c|c|}
\hline $\mathbf{R}^{1}$ & & $\mathbf{R}^{2}$ & $\Delta \mathbf{G}^{*} \mathbf{k J} / \mathbf{m o l e}$ \\
\hline $\mathrm{Me}$ & & $\mathrm{Me}$ & $55.7 \pm 1.1$ \\
\hline $\mathrm{Et}$ & & $\mathrm{Et}$ & $57.1 \pm 1.1$ \\
\hline & & $\left(\mathrm{CH}_{2} \mathrm{CH}_{2}\right)_{2} \mathrm{O}$ & $56.2 \pm 1.1$ \\
\hline & $\left(\mathrm{CH}_{2}\right)_{5}$ & $56.7 \pm 1.1$ \\
\hline & $\left(\mathrm{CH}_{2}\right)_{6}$ & $59.2 \pm 1.2$ \\
\hline
\end{tabular}

Table 1: Gibbs energy of activation $\left(\Delta G^{\neq}\right)$for reversible reaction $\left[R^{1} R^{2} N C O O\right]$.

\begin{tabular}{|c|c|c|}
\hline $\mathbf{R}^{1}$ & $\mathbf{R}^{2}$ & $\Delta \mathrm{H} \mathrm{kJ} / \mathrm{mole}$ \\
\hline Et & Et & $101 \pm 5$ \\
\hline $\mathrm{Pr}$ & $\mathrm{Pr}$ & $189 \pm 9$ \\
\hline Et & cyclo- $\mathrm{C}_{6} \mathrm{H}_{11}$ & $80 \pm 4$ \\
\hline \multicolumn{2}{|c|}{$\left(\mathrm{CH}_{2}\right)_{5}$} & $113 \pm 5.5$ \\
\hline \multicolumn{2}{|c|}{$\left(\mathrm{CH}_{2} \mathrm{CH}_{2}\right)_{2} \mathrm{O}$} & $113 \pm 5.5$ \\
\hline \multicolumn{2}{|c|}{$\left(\mathrm{CH}_{2}\right)$} & $197 \pm 10$ \\
\hline
\end{tabular}

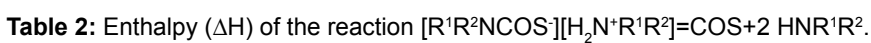

\begin{tabular}{|c|c|c|}
\hline $\mathbf{R}^{1}$ & $\mathbf{R}^{2}$ & $\Delta \mathbf{G}^{\neq} \mathbf{k J} / \mathrm{mole}$ \\
\hline $\mathrm{Me}$ & $\mathrm{Me}$ & $54.8 \pm 1$ \\
\hline Et & $\mathrm{Et}$ & $57.4 \pm 1.1$ \\
\hline $\operatorname{Pr}$ & $\operatorname{Pr}$ & $59.1 \pm 1.2$ \\
\hline Et & cyclo- $\mathrm{C}_{6} \mathrm{H}_{11}$ & $61.4 \pm 1.2$ \\
\hline \multicolumn{2}{|c|}{$\mathrm{C}_{5} \mathrm{H}_{10}$} & $56.6 \pm 1.1$ \\
\hline \multicolumn{2}{|c|}{$\mathrm{C}_{6} \mathrm{H}_{12}$} & $64.0 \pm 1.3$ \\
\hline
\end{tabular}

Table 3: Gibbs energy of activation $\left(\Delta G^{\neq}\right)$for hindered rotation in thio carbamates $\left[R^{1} R^{2} N \operatorname{NOS}^{-}\right]\left[\mathrm{H}_{2} \mathrm{~N}^{+} \mathrm{R}^{1} \mathrm{R}^{2}\right]$.

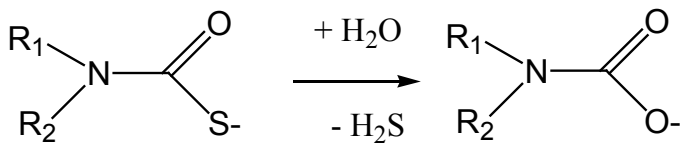

Scheme 5: The main route of hydrolysis of thiocarbamate auto catalysed by $\mathrm{H}_{2} \mathrm{~S}$.

\section{$\Delta \mathrm{G}^{ \pm} 77 \pm 4 \mathrm{KJ} / \mathrm{mole}, \mathrm{X}=\mathrm{O}$}

\section{$69 \pm 3.5 \mathrm{\kappa J} / \mathrm{mole}, \mathrm{X}=\mathrm{S}$}

At the same time the cyclic structure appears to be unrealizable in case of analogues dithiocarbamate despite the fact that it was first proposed exactly for dithiocarbamic acid (Scheme 2). This fact was explained in [18] by antiaromaticity of cyclic dithio carbamate anion because of a strong amide conjugation (Scheme 7). As for more common problems of amine scrubbing, the above mentioned decomposition of 2-aminoethanol in the course of gas purification is responsible for absorbent consumption, reduction of the capacity, and foaming, as well as for accelerated corrosion of the equipment. Since the beginning of the Millennium we have been analyzing NMR spectra of the samples of 2-aminoethanol taken at the scrubbers of oil refinery and at a plant of the production of $\mathrm{CO}_{2}$ in order to identify the products of absorbent degradation and determine its influence on scrubbing efficiency. In 2003 the main product of oxidative degradation of 2-amioethanol at refineries 4-(2-hydroxyethyl) piperazin-2-on was identified by Strazisar [19] and consequently an adequate assignment of signals in NMR spectra became possible. The earlier suggested interpretation of the results of the above mentioned research on identifications and the mechanisms of the degradation underwent a lot of further revisions and corrections [20-23] and the final version of them was published in 2016 Salts of carbamic and thiocarbamic acids $\mathrm{HOCH}_{2} \mathrm{CH}_{2} \mathrm{NHCO}_{2}-\mathrm{H}_{3} \mathrm{~N}^{+} \mathrm{CH}_{2} \mathrm{CH}_{2} \mathrm{OH}$ (1), $\mathrm{HOCH}_{2} \mathrm{CH}_{2} \mathrm{NHCOS}$ $\mathrm{H}_{3} \mathrm{~N}^{+} \mathrm{CH}_{2} \mathrm{CH}_{2} \mathrm{OH}$ (2) $\mathrm{HOCH}_{2} \mathrm{CH}_{2} \mathrm{NHCSS}^{-} \mathrm{H}_{3} \mathrm{~N}^{+} \mathrm{CH}_{2} \mathrm{CH}_{2} \mathrm{OH}$ (3) are formed as the result of interaction of 2-aminoethanol with heterocumulenes $\mathrm{CO}_{2}$, $\mathrm{COSH} \mathrm{CS}_{2}$. In the article a composition of degradation products of 2-aminoethanol during absorption of $\mathrm{CO}_{2}$ was determined, and it was shown that the formation of 1,3-oxazolidine -2one (4) does not occur in operating conditions of industrial plant. Compound (4) is still considered to be the first one on the main route (Scheme 8) of so-called thermal degradation of absorbent. $\mathrm{C}_{13} \mathrm{NMR}$ signals of the compound (4) and common products of its transformation

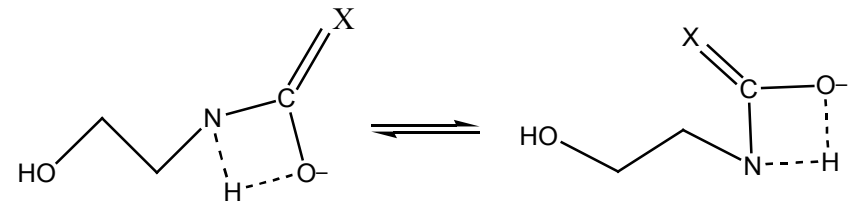

Scheme 6: Pyramidal nitro gene inversion in carbamate and thiocarbamate anionsformed as a resultof the reaction of 2-aminoethanol with $\mathrm{CO}_{2}$ and $\mathrm{COS}$.<smiles>OCC[N+]12[SH]=C1S[IH]2</smiles>

Scheme 7: Anti aromaticity of dithiocarbamate anion induced by an effective amide conjugation.

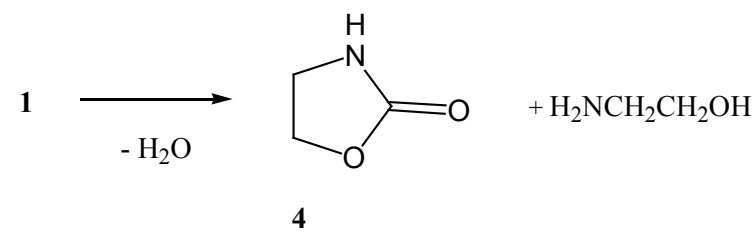

Scheme 8: The first reaction on a common route of carbamate thermal degradation. 
1-(2-hydroxyethyl) imidazolidin-2-one (5), 2-[(2-aminoethyl) amino ethanol (6) had never been detected over years of the plant operating. The below pictured mechanism (Scheme 9) of the compounds (5) and (6) formation was suggested in 1955 [24]. Currently another scheme is considered to be preferable in which imidazolidin (5) is obtained from diamine (6) and is the final product of the degradation [25]. Both of these mechanisms, in our opinion, have no relation to reality in the absence of impurities $\mathrm{COS}, \mathrm{CS}_{2}$ in gaseous stream. An obtaining of oxazolidine (4) from carbamate (1) in relatively mild operating conditions of industrial scrubbers seems unlikely take into account the high pressure applied in a course of analogues reaction during urea production from ammonia and $\mathrm{CO}_{2}$. Some published data agree with this statement [26]. Nevertheless, the compounds (4) - (6) are still considered as the main products of 2-aminoethanol thermal degradation upon absorption of $\mathrm{CO}_{2}$. The reason for this controversy is probably due to the fact that chromatography with mass spectrometry detection: GC-MS, HPLC-MS are mainly used for identification of the compounds (4) (6). Thus, probably, labile salt (1) decays in a course of analysis and products of the decay are taken for degradation products of 2-aminoethanol Furthermore, the compounds (5) and (11) are difficult to distinguish by mass spectra. In the article 2-aminoethanol dissociation into ammonia and ethylene oxide (Schemes 9 and 10) is suggested as the only thermal degradation pathway which leads to ethylene glycol (7) and 2,2 '-iminodiethanol (8). Major products of the 2 -aminoethanol oxidative degradation in the plant for producing carbon dioxide have been also identified. Taking into account additional GC-MS data, other heterocyclic degradation products, such as 2-piperazin-1-ylethanol (11), 1,4-bis(2-hydroxyethyl)piperazine-2,5dione (12) were determined with NMR in addition to previously known formic acid, acetic acid, glycolic acid, oxalic acid, 2-hydroxypropanoic acid, 2-aminopropanoic acid and more specific (2-hydroxyethyl)glycine (9), 4-(2-hydroxyethyl)piperazin-2-on (10). Only listed carboxylic acids were detected by NMR. Resultant (2-hydroxyethyl) amides were determined in the same absorbents by GC-MS The compounds (9), (10) are considered to be the main specific products of the 2 -aminoethanol oxidative degradation The shortest route of amino acid (9) formation is the reaction of 2-aminoethanol with glyoxal (a kind of Cannizzaro reaction (Scheme 11) published earlier, although a different mechanism has recently been proposed Reactive glyoxal is likely formed from glycolic acid, which prevails in the mixture of carboxylic degradation products described by the reverse Cannizzaro reaction and reacts with 2-aminoethanol to give amino acid (9) Formation of the compound (12) is explained in by the next reaction (Scheme 12). It was proposed that the following amidation and dehydration (Scheme 13) were involved in the compound (10) formation The redox reaction catalyzed by $\mathrm{Fe}^{2+, 3+}$ ions was the first suggested The reactions at the Scheme 13 cannot explain the formation of piperazine (11) which content is essentially higher than that of piperazinone (10) in absorbents taken in the plant for $\mathrm{CO}_{2}$ production. We also do not see a driving force of dehydration (Scheme 13) leading to the substance (10) in the absence of acid catalysis. In our opinion, the following $\mathrm{Fe}^{2+, 3+}$ catalyzed hydration of amide (13) (Scheme 14) can yield diamine (14). This reaction, hydro ammonolysis, is applied in industry for production of amines from carboxylic acids Intermediates (13)(14) give piperazines (10), (11) as the result of another hydro ammonolysis (Scheme 15) which is applied in industry for production of amines from spirits. It has recently been proposed that the compound (10) may yield bicine ( $\mathrm{N}, \mathrm{N}$-bis(2-hydroxyethyl)glycine) (15) as the result of the following transformations Scheme 16. Bicine is considered to be the most dangerous component of the adsorbent from the point of view of corrosion of equipment. We have failed to detect bicine with NMR but it has been detected with GS-MS in the sample of the absorbent which caused emergency corrosion in a plant for $\mathrm{CO}_{2}$ production. Pyperazinone (10) was the main product of 2 -aminoethanol oxidative<smiles>NCCOC(=O)C(=O)OCCN1CCNC1=O</smiles>

Scheme 9: The oldest suggested mechanism of the last studies of the main route of thermal degradation of 2 aminomethanol in a process of amine scrubbing.

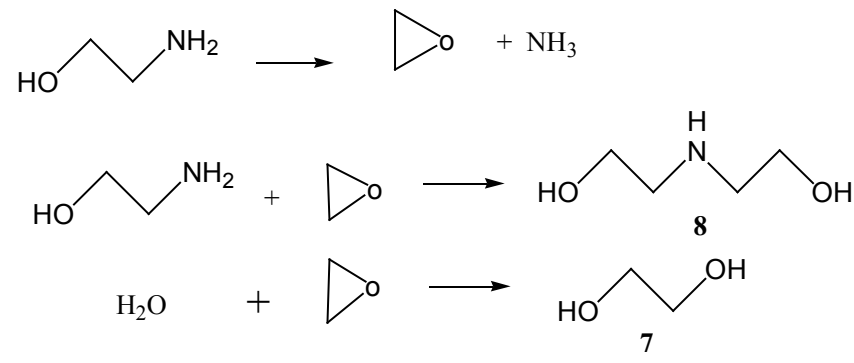

Scheme 10: The main routes of 2 aminoethanol thermal degradations in the absence of $\mathrm{COs}$ and $\mathrm{CS}_{2}$ in gaseous streams.

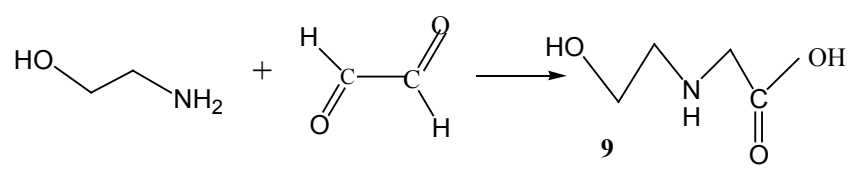

Scheme 11: One of the suggested mechanism of glycine formation.

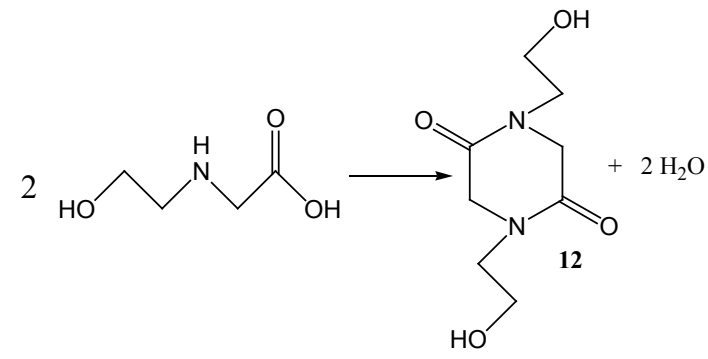

Scheme 12: Obvious mechanism of compound 12 obtaining.

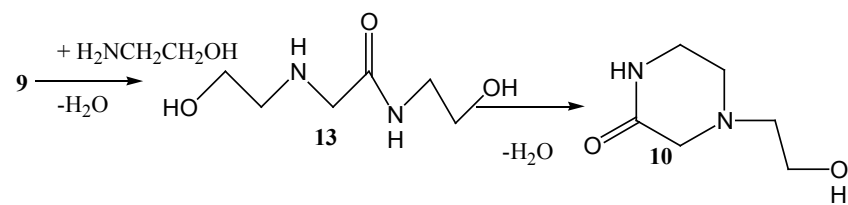

Scheme 13: Common mechanism of piperazinone formation. 
degradation at scrubbers at a local oil refinery with the exceptions of scrubbers operating at hydrotreating plants. The compound (9) was also found in some samples of absorbent. But signals of the compounds (11), (12) which prevail in the series of the compounds (9) -(12) at the plant for $\mathrm{CO}_{2}$ production were never found at the oil refinery. The fact is likely connected with the presence of $\mathrm{H}_{2} \mathrm{~S}$ and $\mathrm{SO}_{2}$ in refinery gaseous streams. Oxalic acid and in some samples also acetic acid and $\mathrm{N}-(2-$ hydroxyethyl) acetamide were found with NMR in absorbent at refinery scrubbers with the exceptions of hydrotreating plants. The main problem of amine scrubbing at the refinery we have been facing is an absorbent foaming which is traditionally attributed to the oil-products fouling. This common explanation is quite unconvincing. We have been trying to identify a surfactant formed during 2-aminoethanol degradation. It took us many years and required four interations. At present, two detected ${ }^{13} \mathrm{C}$ NMR signals (60.45 and $41.40 \mathrm{ppm}$ ), which were earlier attributed to the salt (2) then to (2-hydroxyethyl) amides of oxalic and acetic acids, are assigned to the compound (16) given below (Scheme 17) which is formed as the result of well known- in a case of $\mathrm{CS}_{2}$ (Scheme 1). The compound (16) is a very good candidate for the role of a surfactant wanted. Its molecule obviously contains hydrophobic (S-S-) and hydrophilic $\left(\mathrm{NHCH}_{2} \mathrm{CH}_{2} \mathrm{OH}\right)$ parts. Very good correspondence between simulated and real spectra of disulfide (16) cannot serve as a reliable argument to the rightness of its identification bearing in mind the number of previous wrong versions. But there are other arguments that are much more reliable. Signals attributed to the compound (16) were never detected in case of gaseous streams which obviously did not contain COS. The signals in question appear immediately in ${ }^{13} \mathrm{C}$ NMR spectra at room temperature after saturation of absorbent with COS. A relative intensity of signals is higher in the samples of heavily foaming absorbents. The 2 -aminoethanol oxidative degradation products were not detected at scrubbers of hydrotreating plants which deal mainly with $\mathrm{H}_{2} \mathrm{~S}$ in gaseous streams. The reason can be strong reductive properties of $\mathrm{H}_{2} \mathrm{~S}$. It was shown earlier that oxazolidine (4) was easily obtained at saturation of 2-aminoethanol solution with COS. In case of the solution heating or long exposure, the compound (4) yields N,N'-bis(2-hydroxyethyl)thiourea (17). Urea (17) is usually the main product of 2 -aminoethanol thermal degradation at refinery scrubbers with the exception of hydrotreating plants. $\mathrm{C}_{13} \mathrm{NMR}$ signals of the compounds (2), (4) were never observed in spectra of refinery absorbents. The compound (4) is unstable in industrial conditions but can take its time for its transformation into urea (17). In some cases urea turns into the compounds (5), (6) completely. The below mechanism Scheme 18 was proposed in 1975 to explain the compounds (4) -(6), (17) obtaining in case of $\mathrm{CO}_{2}$ absorption [27]. The suggested mechanism still seems to be the most adequate but with the essential elaborations. A source of the compounds (4) is thiocarbamate (2) or dithiocarbamate (3) (see below) but not carbamate (1). Transformation of urea (17) into compound (5) (Scheme 18, reaction 3) seems unlikely to be simple dehydration. We consider this cyclization is also catalytic hydro ammonolysis. That can be the reason why we have failed in reproducible obtaining of the compound (5) by heating the solutions of urea (17) in the laboratory It has been noted in the article that probability of urea (17) transformation into compounds (5), (6) increases alongside with the rise of the concentration of the substance which is currently attributed to the disulfide structure (16). The oxidative dehydration, which is necessary for the reaction 3 and reaction 1 (Scheme 17) to occur, is likely catalyzed by the same iron complexes. The compounds (4)-(6), (17) were completely absent in absorbents of hydrotreating scrubbers. The main reason is likely to be an absence of COS and CS in gaseous streams. Shown in autocatalytic nature of thiocarbamate (2) hydrolysis with respect to $\mathrm{H}_{2} \mathrm{~S}$ can be another reason. Only weak ${ }^{13} \mathrm{C}$ NMR signals of amine (8) and salt (1) were detected in spectra of 2-aminoethanol solutions at hydrotreating plant scrubbers. Refinery gaseous streams contain $\mathrm{CS}_{2}$ which yields the salt (3) when it reacts with 2-aminoethanol. In earlier publications. we have made several rough mistakes in the attempts to identify the salt (3) and the products of its transformations in refinery absorbents. Only recently ${ }^{13} \mathrm{C}$ NMR signals of the salt (3) and amine (8) have clearly been distinguished. It turns out that dithiocarbamate (3) and the products of its transformation which are thio analogues of the compounds (4), (5), (17) (Scheme 18) cannot be detected with NMR in refinery absorbents. Thio analogues of interest have been detected only by GS-MS in the same absorbents. It cannot be excluded that some of them are formed as a result of salt (3) decay in a process of analysis. A reliable fact is hydrolysis of the salt (3) to the salt (2) then successively and similarly to the salt (1) Scheme 5 with parallel formation of compound (4) at scrubbing conditions. An adequate composition of the main products of 2-aminoethanol degradation in the process of industrial scrubbing has been elucidated relatively recently. The mechanisms of the main and side reactions that determine chemistry of this important technology have been refined step by step. However, optimal technological regulations and measures to reduce harmful effects of absorbent degradation have been developed as a result of many decades of the
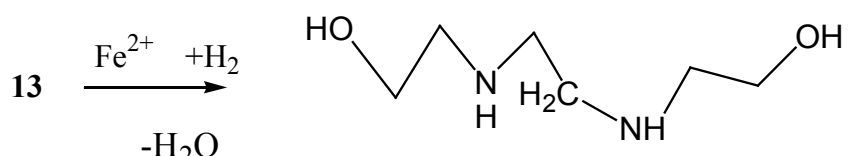

14

Scheme 14: The formation of intermediate in the result of hydroammonolysis of glycine.
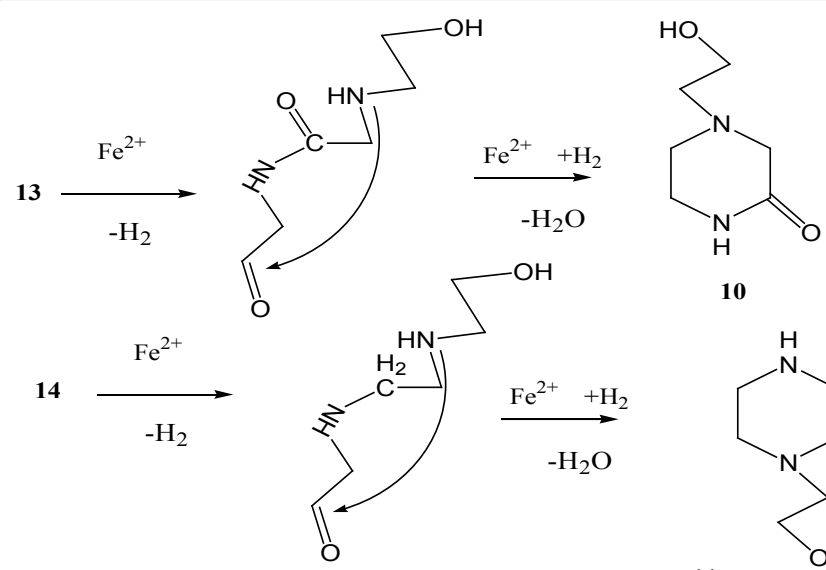

10

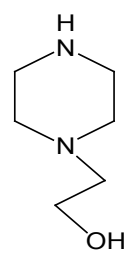

Scheme 15: Mechanisms of piperazines formation in the result of intra molecular hydroammonolysis.

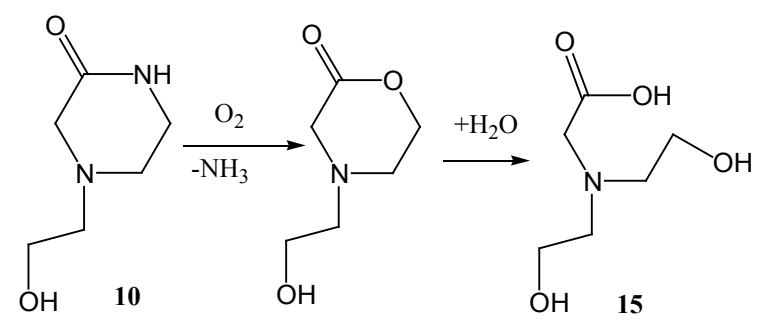

Scheme 16: The seeming to be reasonable mechanism of bizine formation from the main product of 2 amino ethanol oxidative degradation. 
<smiles>O=C(NCCO)SSC(=O)SC(=O)NCCO</smiles>

Scheme 17: The formation of suggested disulphide surfactant in the result of thiocarbamate anion oxidation.

$$
17 \stackrel{\mathrm{H}_{2} \mathrm{~S}}{\longrightarrow}
$$

Scheme 18: The mechanism of thermal degradation of 2 aminoethanol in apresence of cos in gaseous streams.

amine scrubbing industrial application. Various methods of absorbent purification as well as corrosion inhibitors and anti-foaming agents have been implemented. In some cases, if chemistry and economics made it possible, 2 -aminoethanol has been replaced for secondary and tertiary ethanolamines, that are more resistant to decomposition, or for other more expensive amines. And yet the new information obtained recently about the structure and composition of the main and minor compounds formed in the process of amine scrubbing can be useful taking into account that the process has no alternative at usually found concentrations of acidic admixtures in technological gases.

\section{References}

1. Kohl AL, Riesenfeld FC (1960) Gas Purification. New York, McGraw Hill.

2. Zoannou KS (2011) Aspects of Degradation of Monoethanolamine Solutions during $\mathrm{CO}_{2}$ Absorption. Cardiff University.

3. Vevelstad SJ, Grimstvedt A, Knuutila H (2014) Influence of experimental setup on amine degradation. Int J Greenh Gas Control 28: 156.

4. Fytianos G, Ucar GSA, Hallvard G, Svendsen F (2016) Corrosion and degradation in MEA based post-combustion $\mathrm{CO}_{2}$ Capture. Energy Procedia 46: 48-56.

5. Lebedev NN (1988) Chemistry and technology of basic organic and petroleum synthesis. Moscow. Chemistry, p: 588

6. Jencks WP (1970) Catalysis in Chemistry and Enzymology 168: 1080-1081.

7. Jonson SL, Morrison DL (1972) Kinetics and mechanism of $\mathrm{N}$-aryl carbamates Evidence for kinetica important zwitterionic carbamic acid species of short lifetime. J Amer Chem Soc 94: 1323-1334.

8. Sharma MM (1965) Kinetics of reactions of carbonyl sulphide and carbon dioxide with amines and catalysis by Bronsted bases of the hydrolysis of COS Trans Faraday Soc 61: 681-688.

9. Cristiany F, Devillanova FA, Verany G (1977) N-C bond cleavage in the acid- catalyzed decomposition of some dithio- and diselenocarbamates. A kinetic investigation of dithio carbamate decomposition in benzene and methanol. Tetrahedron 33: 1003-1006.

10. Cristiany F, De Fillipo D, Devillanova FA (1975) Gazzetta chimica italiana 105: 603

11. Zahradnik R, Zuman P (1959) Carbamates monothiocarbamates and dithiocarbamates VIII. Polarographic study of the kinetics and the mechanism of decomposition of dithiocarbaminic acids in acidic medium. Coll Chech Chem Comm 24: 1132-1139.

12. Joris SJ, Aspila KT, Chakrabarty CL (1969) Monobasic and dibasic character of dithio carbamic acids. Anal Chem 41: 1441-1145

13. Sh P, Ewig D, Lockson WP (1980) Mechanism of cleavage of carbamic anions. J Amer Chem Soc 102: 3072-3080

14. Savin VP, Talzi VP, Bek NO (1984) The investigation of the heterocumulenes $\mathrm{CO}_{2}, \mathrm{COS}, \mathrm{CS}_{2}$ interaction with secondary amines with ${ }^{1} \mathrm{H},{ }^{13} \mathrm{C}$ NMR. Zh Org Khim 20: $1842-1848$

15. Glazirin AB, Talzi VP, Denisov EN, Imashev UB (1985) The study of the hydrolysis of $\mathrm{Na}$ salt of hexamethylene thiocarbamic acid. Russ J Appl Chem 58: $2300-2304$

16. Glazirin AB, Kuramshin EM, Denisov EN, Imashev UB (1986) The investigation of decomposition of sodium salt of hexamethylene thio carbamic acid in aqueous medium. Russ J Appl Chem 59: 1076-1082.

17. Talzi VP (2016) NMR study of the composition of aqueous 2-aminoethano solution used for absorption of carbon dioxide from fuel gases. Zh Org Khim 52: $927-931$.

18. Talsi VP, Evdokimov CN (2016) The investigation of pyramidal nitrogen inversion in carbamate and thiocarbamate ions formed as the result of the reaction of $\mathrm{CO}_{2}, \mathrm{COS}, \mathrm{CS}_{2}$ with 2-aminoethanol. Zh Org Khim.

19. Strazisar BR, Anderson RR, White CM (2003) Degradations pathways for mono ethanolamine in a CO2 capture facility. Energy Fuels 17: 1034-1039.

20. Talzi VP, Ignashin SV (2002) NMR Study of Decomposition of Mono ethanolamine under Conditions of Industrial Gas Treatment. Russ J Appl Chem of the USSR 75: 80-85.

21. Talzi VP (2004) NMR determination of the total composition of commercia absorbents based on mono ethanolamine. Russ $\mathrm{J}$ Appl Chem of the USSR 77: 430-434

22. Talzi VP (2010) The investigation of the monoethanolamine degradation products during sweetening. Khim Promst, pp: 89-95.

23. Talzi VP (2014) Investigation of product composition produced by degradation of monoethanolamine in absorption cleaning of exhaust gases. Khim Promst pp: $244-249$.

24. Polderman LD, Dillon CP (1955) Why monoethanolamine solution breaks down in gas treating service. Proc Gas Conditioning Conf, pp: 49-56.

25. Davis J (2009) Thermal degradation of Aqueous Amines Used for Carbon Dioxide Capture. University of Texas at Austin, USA.

26. Lepaumier H, Silva EF, Einbu A (2011) Comparison of MEA degradation inpilotscale with lab-scale experiments. Energy Procedia 4: 1652-1659.

27. Yavzikova NV, Zelenskaya LG, Balyasnikova LV (1975) Mechanism of Side Reactions during Removal of Carbon Dioxide from Gases by Treatment with Mono ethanolamine. Journal of Applied Chemistry of the USSR 48: 674-676. 